\title{
Oblique Internal Hydraulic Jumps at a Stratified Estuary Mouth $\mathscr{O}$
}

\author{
DAvid A. Honegger AND Merrick C. HALler \\ School of Civil and Construction Engineering, Oregon State University, Corvallis, Oregon \\ W. ROCKWELL GEYER \\ Applied Ocean Physics and Engineering, Woods Hole Oceanographic Institution, Woods Hole, Massachusetts \\ GORDON FARQUHARSON \\ Applied Physics Laboratory, University of Washington, Seattle, Washington
}

(Manuscript received 1 December 2015, in final form 30 September 2016)

\begin{abstract}
Observations and analyses of two tidally recurring, oblique, internal hydraulic jumps at a stratified estuary mouth (Columbia River, Oregon/Washington) are presented. These hydraulic features have not previously been studied due to the challenges of both horizontally resolving the sharp gradients and temporally resolving their evolution in numerical models and traditional observation platforms. The jumps, both of which recurred during ebb, formed adjacent to two engineered lateral channel constrictions and were identified in marine radar image time series. Jump occurrence was corroborated by (i) a collocated sharp gradient in the surface currents measured via airborne along-track interferometric synthetic aperture radar and (ii) the transition from supercritical to subcritical flow in the cross-jump direction via shipborne velocity and density measurements. Using a two-layer approximation, observed jump angles at both lateral constrictions are shown to lie within the theoretical bounds given by the critical internal long-wave (Froude) angle and the arrested maximum-amplitude internal bore angle, respectively. Also, intratidal and intertidal variability of the jump angles are shown to be consistent with that expected from the two-layer model, applied to varying stratification and current speed over a range of tidal and river discharge conditions. Intratidal variability of the upchannel jump angle is similar under all observed conditions, whereas the downchannel jump angle shows an additional association with stratification and ebb velocity during the low discharge periods. The observations additionally indicate that the upchannel jump achieves a stable position that is collocated with a similarly oblique bathymetric slope.
\end{abstract}

\section{Introduction}

Adequate sampling of estuarine processes via moored or even moving (e.g., shipborne) measurement platforms can require extensive, prior, local knowledge, as some of these processes can vary in both the along- and cross-channel directions (Klymak and Gregg 2001). Of these, sharp density and flow gradients are especially challenging to resolve, both numerically (e.g., Hofmeister et al. 2010; Kärnä et al. 2015) and observationally, yet

Supplemental information related to this paper is available at the Journals Online website: http://dx.doi.org/10.1175/ JPO-D-15-0234.s1.

Corresponding author e-mail: David A. Honegger, honegged@ oregonstate.edu they can be important when channel geometry does not vary smoothly. Klymak and Gregg (2001) found counterrotating eddies in the lee of a sill and narrows in Knight Inlet that caused significant biases in their along-channel estimates of volume flux. MacDonald and Geyer (2005) found first-order, cross-channel variability in the Fraser River ebb plume liftoff zone as well, and a 3D simulation of the Strait of Gibraltar highlighted sharp horizontal flow and density gradients oriented obliquely to the channel (Sánchez-Garrido et al. 2011).

Remote sensors such as imaging radars detect the surface attributes of sharp flow gradients and can therefore offer spatial context in both horizontal directions simultaneously. Processes previously analyzed via observation of their surface attributes include coastal oceanic fronts (e.g., Marmorino et al. 1998), ebb plume fronts (e.g., Pan and Jay 2009), tidal intrusions 
(e.g., Marmorino et al. 1999), and internal waves (e.g., Watson and Robinson 1990; Chang et al. 2008; Ramos et al. 2009). These internal features are detected by radars due to the modulations of horizontal surface divergence and strain, which amplify or attenuate the Bragg resonant surface waves. The resulting patterns of the surface roughness map directly to patterns in imaged radar backscatter intensity (e.g., Lyzenga 1998).

Internal hydraulic jumps constitute an exemplary case of sharp, horizontal density and flow gradients and have been observed in stratified flows both in the atmosphere (e.g., Drobinski et al. 2001; Armi and Mayr 2011) and oceans and estuaries (Partch and Smith 1978; Farmer and Smith 1980; Klymak and Gregg 2001; Nash and Moum 2001; Cummins et al. 2006; Cummins and Armi 2010; Sumner et al. 2013). Internal jumps are essentially arrested internal bores and are regions of rapidly varying flow that mark the transition from internally supercritical to subcritical conditions (e.g., Baines 1998). In supercritical flow conditions, obliquely oriented hydraulic jumps may occur (e.g., Ippen and Harleman 1956; Garvine 1982), in analogy to shock waves in supersonic flows. Since disturbances generated in the supercritical flow cannot propagate directly upstream, they instead accumulate along a hydraulic jump oriented at an angle that is oblique to the flow direction. Dominant jump balances occur in the cross-jump $x_{j}$ and vertical $z$ directions, and so while the processes are not strictly $3 \mathrm{D}$, an oblique hydraulic jump can be classified as quasi-3D because the intrinsic dynamics are oriented at an angle to the larger-scale dynamics (along estuary $x$ and across estuary $y$ ).

The early work of Ippen and Harleman (1956) showed that, for barotropic flows, this angle is oriented along a critical transition in the cross-jump direction. Further analytic and laboratory experimental work by Akers and Bokhove (2008) and Defina and Viero (2010) found good model/data agreement of observed jump angles when finite-amplitude effects were included. These effects increase the bore speed (and thereby decrease the corresponding jump angle). However, these results were again for barotropic (single layer) jumps. The analogous approach in stratified flows, which treat oblique internal hydraulic jumps as arrested, long, interfacial waves, has not received as much attention, though the general concept has been used with some success to describe observed obliquity of ebb plume fronts at the surface (Garvine 1981, 1982) and at the bottom (MacDonald and Geyer 2005). There are notably few observations of oblique internal jumps in marine environments. Klymak and Gregg (2001) noted lateral variability in an internal jump at Knight Inlet and Sánchez-Garrido et al. (2011) inferred the presence of oblique internal jumps along lateral boundaries in simulations of Strait of Gibraltar hydraulics during ebb and flood

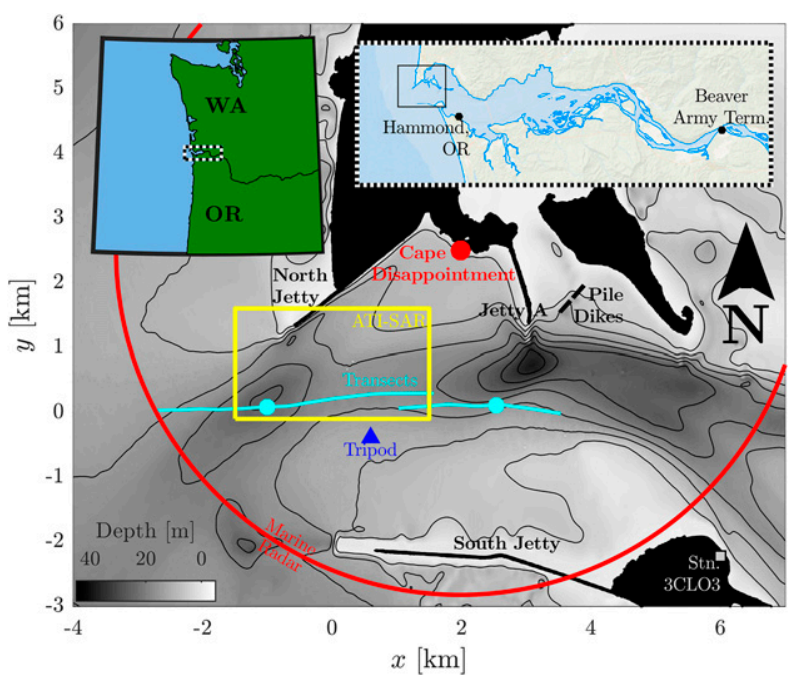

FIG. 1. Study area. Grayscale colored bathymetry Columbia River mouth (NGDC Astoria Inundation Digital Elevation Map; see www.ngdc.noaa.gov) with 5-m contour separation. Land is masked at the mean high water line. Engineered structures are labeled (Jetty A, North Jetty, South Jetty, and pile dikes). Location of X-band marine radar (filled red circle at Cape Disappointment) with observation footprint (red circle), ATI-SAR surface current domain (yellow box), moored tripod (blue triangle), ship transects (cyan curves), and observed jump locations in shipboard transect data (cyan circles). Insets indicate (top left) Columbia River location in northwest United States and (top right) intermediate zoom showing tide (Hammond, Oregon) and discharge (Beaver Army Terminal) measurement locations.

conditions. Geyer et al. (1997) observed angled fronts near sharp lateral bathymetry gradients in the Hudson River.

Herein, we present and synthesize an extensive set of observations of recurring, oblique. internal hydraulic jumps that extend from lateral boundary constrictions at the mouth of a large, stratified estuary. The mouth of the Columbia River (MCR) is located at the coastal boundary between Oregon and Washington, United States (Fig. 1, inset). At this location, strong freshwater discharge meets an energetic surface wave climate across a complex domain. Rapid, highly sheared tidal currents flow past a channel bend in the presence of longitudinally and laterally variable bathymetry and engineered lateral constrictions. The observations focus on oblique, internal hydraulic jumps near two constrictions caused by jetties extending from the northern side of a bend in the main channel. The importance of a lateral control in the vicinity of Jetty A was suggested by Cudaback and Jay (1996), but their analysis was limited to strictly alongchannel transitions.

In the present work, we compare remotely sensed and in situ observations of two oblique, internal, hydraulic jumps with a two-layer, inviscid, Boussinesq flow model. Using the celerities of a small-amplitude long wave 
(e.g., Armi 1986) and a maximum-amplitude (conjugate state) bore (e.g., Lamb 2000) to bound the amplitudedependent variability of the critical condition, we demonstrate the presence of a critical transition across these jumps. The corresponding upper and lower bounds on jump angles to the flow are then used to characterize the imaged backscatter intensity features as oblique internal jumps. Continuous remote sensing observations of the two jumps during the annual maximum (May-June) and minimum (September) freshwater discharge periods are then used to analyze intratidal to interseasonal variability in jump occurrence and angle. This article is organized as follows: Section 2 contains a review of two-layer hydraulic theory concerning oblique, internal, hydraulic jumps. The observations program is described in section 3 , with the observational results, comparison against two-layer theory, and discussion of the shape, location, and variability of the jumps then following in section 4 .

\section{Oblique hydraulic jumps}

An oblique, internal hydraulic jump is a shock wave that emanates from a persistent disturbance to internally supercritical, stratified flow. Characteristics originating at the disturbance can approach (but not cross) the oblique shock, accumulating into an arrested internal bore. ${ }^{1}$ The celerity of this bore governs the angle at which it is arrested by the ambient flow and thereby the jump's orientation to the flow direction.

In this $2 \mathrm{D}$ characterization, it is assumed that crossjump balances dominate, and this is supported by laboratory flume experiments of the barotropic (free surface) mode (Ippen and Harleman 1956). The angle of oblique barotropic hydraulic jumps was characterized as the critical angle at which the cross-jump component of the incident mean flow $U_{j}=\mathbf{U} \cdot \hat{\mathbf{n}}=|\mathbf{U}| \sin \Theta$ balances the intrinsic long-wave speed $\sqrt{g H}$. Here, $g$ is gravitational acceleration, $H$ is the total fluid depth, $\mathbf{U}$ is the depth-averaged current vector, $\hat{\mathbf{n}}$ is the jump normal unit vector, and $\Theta$ is the angle between the flow and along-jump directions. This arrest of the absolute long-wave speed (relative to a fixed observer) $C_{0}=U_{j}+\sqrt{g H}=0$ was compactly stated as

$$
\Theta_{0}=\sin ^{-1} \frac{1}{\mathrm{Fr}},
$$

\footnotetext{
${ }^{1}$ In the present context, the terms "hydraulic jump" and "bore" refer to the same hydraulic feature but with subtle emphasis of the latter on a feature that propagates relative to an observer. We therefore refer to a hydraulic jump as an arrested bore.
}

where $\Theta_{0}$ is the modeled barotropic long-wave jump angle, and $\mathrm{Fr}=|\mathbf{U}| / \sqrt{g H}$ is the Froude number.

A similar concept can be applied to internal hydraulic jumps, wherein the interfacial long-wave speed is

$$
c_{0}=\frac{u_{1} h_{2}+u_{2} h_{1}}{H} \pm\left\{g^{\prime} \frac{h_{1} h_{2}}{H}\left[1-\frac{\left(u_{1}-u_{2}\right)^{2}}{g^{\prime} H}\right]\right\}^{1 / 2}
$$

for an inviscid, Boussinesq, two-layer, sheared flow (e.g., Armi 1986). As shown in Fig. $2 b, g^{\prime}=g\left(\rho_{1}-\rho_{2}\right) / \rho_{1}$ is reduced gravitational acceleration, $\rho_{i}$ are the layer densities, $u_{i}$ are the layer velocities, and $h_{i}$ are the layer thicknesses. Subscripts 1 and 2 on the velocities and layer depths correspond to the lower and upper layers and note that lowercase letters are used to denote baroclinic variables where a distinction is required. The critical condition $c_{0}=0$ can be compactly represented with internal Froude numbers as (Armi 1986)

$$
G^{2} \equiv \mathrm{Fr}_{1}^{2}+\mathrm{Fr}_{2}^{2}=1 ; \quad \operatorname{Fr}_{i} \equiv \frac{u_{i}^{2}}{g^{\prime} h_{i}}, \quad i=1,2
$$

where $\mathrm{Fr}_{i}$ are the individual layer internal Froude numbers, and $G$ is the composite internal Froude number. Using the cross-jump component of each layer's velocity $u_{j i}=u_{i} \sin \theta$, where $\theta$ is the angle between the flow direction and the baroclinic jump, the critical jump angle of the inviscid, Boussinesq, two-layer long wave is then (e.g., MacDonald and Geyer 2005)

$$
\theta_{0}=\sin ^{-1} \frac{1}{\mathrm{G}}
$$

Oblique shock conditions such as this have been used to model and characterize both surface and bottom fronts at estuary mouths. Froude number-based front angle control was developed by Garvine (1981) to model the position of a persistent buoyant river outflow front in the presence of an ambient cross current as well as by MacDonald and Geyer (2005) to characterize the angle of an arrested bottom front of the Fraser River liftoff zone. Correspondence between observations and the remarkably simple theory demonstrates its utility in characterizing these internal hydraulic phenomena.

The long-wave speed, however, neglects the nonlinear celerity amplification of finite-amplitude bores and can therefore result in an underestimate of the jump angle. Arrest of a larger-amplitude, fastermoving jump requires stronger incident flow; supporting evidence was illustrated in Cummins et al. (2006, cf. 

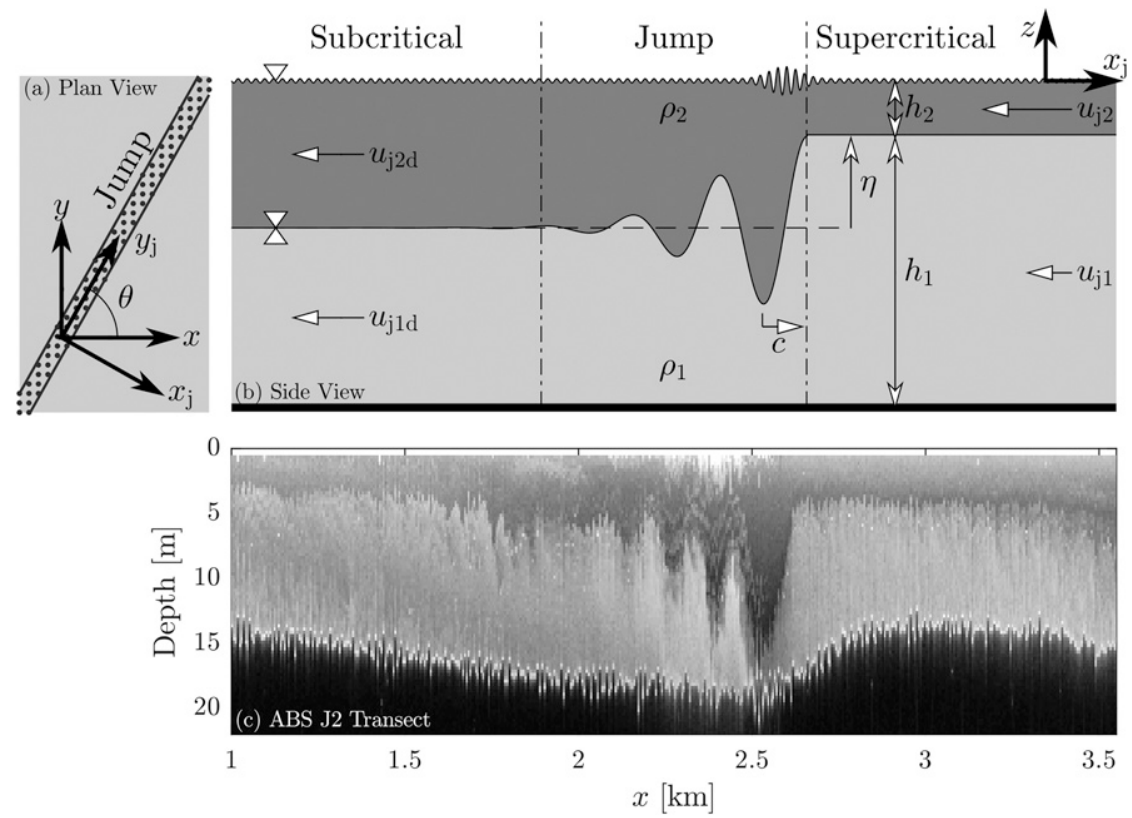

FIG. 2. Flow schematic and example jump in a fixed reference frame: (a) plan view shows the relationship between jump angle $\theta$, cross- and along-jump directions $\left(x_{j}, y_{j}\right)$ and along- and cross-channel directions $(x, y)$ and (b) side view shows a cross section of an upper-layer internal bore with overall amplitude $\eta$, propagating into counterflowing fluid with layer velocities $u_{i}$, thicknesses $h_{i}$, and densities $\rho_{i}$. In the fixed reference frame, the bore is arrested (forming a stationary internal hydraulic jump) when $c=0$. Surface roughness is enhanced in the convergent zone at the head of the jump. (c) ABS intensity transect of J2, showing jump structure between upper (medium gray) and lower (light gray) layers. Note that the horizontal scale of the transect is larger than that of the schematic side view and that high-frequency fluctuations along the bottom and interface result from vessel motion due to approximately 1.4-m surface waves (NDBC buoy 46243 , located $4 \mathrm{~km}$ offshore).

their appendix B), wherein nonhydrostatic simulations showed that a finite-amplitude internal bore achieved a quasi-stationary, along-channel position in the presence of steady upstream flow with an internal Froude number greater than 1.5. In this simulation, the amplified bore speed balanced the incident supercritical flow rather than the long-wave speed. Subsequent observations have supported this result (Cummins and Armi 2010). Note that a critical transition still occurs across a finiteamplitude hydraulic jump, such that information originating downstream can accumulate at and reinforce the jump.

Analytical models of oblique, barotropic, hydraulic jumps now regularly use the finite-amplitude absolute bore speed $C_{b}=\sqrt{g H\left[(1 / 2)+\left(\eta / h_{u}\right)\right]\left[1+\left(\eta / h_{u}\right)\right]}+U_{j}$, where $\eta$ is the bore amplitude, and $h_{u}$ is the upstream water depth (e.g., Chaudhry 2007; Akers and Bokhove 2008; Defina and Viero 2010). It is appropriate to apply a similar extension to the internal oblique hydraulic jump. For instance, the internal bore model of Yih and Guha (1955) was used as the basis of the buoyant plume front relations of Garvine
(1981), although in order to arrive at these relations an infinitely deep lower layer was assumed, and the limiting case of $h_{2} \rightarrow 0$ was applied. In contrast, internal hydraulic jump angles exhibit finite, upstream, upper-layer thickness and finite total depth. We limit our scope to the maximum-amplitude (conjugate state) bore, which has absolute celerity given by (Lamb 2000)

$$
c_{b}=\frac{1}{2} \sqrt{g^{\prime} H}+\frac{1}{2}\left(u_{1}+u_{2}\right) .
$$

This bore is arrested when $c_{b}=0$, which corresponds to the maximum-amplitude jump angle:

$$
\theta_{b}=\sin ^{-1} \frac{1}{G_{b}}
$$

where $G_{b}=\left(u_{1}+u_{2}\right) / \sqrt{g^{\prime} H}$. In a Boussinesq fluid, this solution approximately corresponds to the maximum celerity bore (White and Helfrich 2014; Ogden and Helfrich 2016; Baines 2016). The angle $\theta$ of an oblique, internal hydraulic jump in a two-layer, inviscid, 


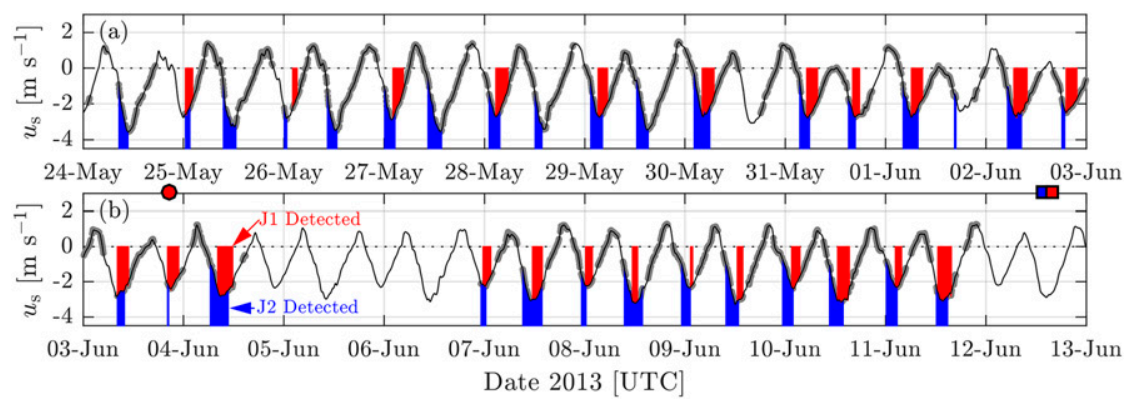

FIG. 3. Velocity (upper 2-m mean) at the mooring (thin black line) and visual jump detections from radar (J1 light red lines, J2 light blue lines). ATI-SAR overflight of J1 (red circle), vessel transect times on 12 Jun shown as squares for J1 (red) and J2 (blue). Radar observation times indicated by thick gray dots on velocity time series.

Boussinesq fluid can therefore be expected to lie within the range $\theta_{0}<\theta \leq \theta_{b}$.

\section{Observations}

Data were collected at the Columbia River Mouth during 24 May-12 June 2013, part of two, concurrent, multidisciplinary, and multi-institutional experiments, Data Assimilation and Remote Sensing for Littoral Applications (DARLA; Jessup et al. 2012) and River and Inlet Dynamics (RIVET-II), with the overall purpose of better understanding the dynamics of energetic, stratified inlet environments. The subset of observation systems used herein is a shore-based, imaging, X-band marine radar; an airborne, along-track, interferometric, synthetic aperture radar (ATI-SAR); a bottommounted mooring; and a vessel (R/V Westwind) performing transects with an ADCP and a CTD. Spatial data coverage is shown in Fig. 1. We define a local coordinate system at the MCR as a translational offset of UTM zone 10T, such that the origin roughly bisects the North and South Jetties. The control point of the coordinate system is the Cape Disappointment Lighthouse $\left(46.2758^{\circ} \mathrm{N}, 124.0521^{\circ} \mathrm{W}\right)$, located at $(x, y)=(2.0 \mathrm{~km}$, $2.5 \mathrm{~km}$ ). Data were collected during the spring freshet, a period of the annual maximum freshwater discharge in the Columbia River. The mean discharge was $9400 \mathrm{~m}^{3}$ $\mathrm{s}^{-1}$ (Beaver Army Terminal, USGS station 14246900, $\sim 80 \mathrm{~km}$ upriver near Quincy, Oregon) during 24 May12 June, $45 \%$ more than the 2013 mean annual discharge of $6500 \mathrm{~m}^{3} \mathrm{~s}^{-1}$. The data collection period spanned a spring-neap cycle, including some of the largest tidal ranges of the year (up to $3.8 \mathrm{~m}$ and as low as $1.2 \mathrm{~m}$, measured at NOAA station 9439011 in Hammond, Oregon), and correspondingly strong ebb flows (Fig. 3). Near-surface ebb flow extrema during the observation period ranged between 2 and $3.75 \mathrm{~m} \mathrm{~s}^{-1}$. The additional freshwater input of the spring freshet contributes to buoyancy in the estuary, whereas the large tidal range supports greater barotropic forcing and hence mixing and decreased stratification. Wind data were acquired from MesoWest Station 3CLO3, located on the south shore of the MCR.

The X-band marine radar was located atop the watchtower at U.S. Coast Guard Station Cape Disappointment, overlooking the northern shore of the Columbia River mouth. The horizontally polarized $(\mathrm{HH})$ X-band $(9.45 \mathrm{GHz})$ radar rotates at approximately $48 \mathrm{rpm}(0.8 \mathrm{~Hz})$, such that the water surface is sampled every $1.25 \mathrm{~s}$. Internally the data acquisition software oversamples $12-\mathrm{m}$ range resolution to $3-\mathrm{m}$ bins and averages seven pulses, resulting in $2^{\circ}$ azimuthal resolution. Image time series of X-band backscatter intensity were collected once or twice per hour in continuous bursts ranging between 512 and 2048 rotations in duration (11 to $42 \mathrm{~min}$ ). Times during which the radar collected data are plotted in gray in the lower panels of Fig. 3 and overlie the tidal currents. To filter out the oscillatory signal from surface gravity waves, the raw image time series were low-pass filtered using a moving 48 rotation $(\sim 60 \mathrm{~s})$ mean. Contrast was increased by reducing the intensity scale from $[0,255]$ to $[15,150]$ in the displayed images. Jump orientation and associated uncertainty was estimated via subimage Radon transform (see appendix); the percentage of estimates that survived quality control for the downchannel jump and the upchannel jump was $76 \%$ and $62 \%$, respectively.

A concurrent snapshot of the ebbing surface current field near the North Jetty was collected via the ATISAR (Farquharson et al. 2014) overflight during 20282048 UTC on 3 June 2013 (Fig. 3, red circle). The ATISAR measures the Doppler shift induced by advected scattering roughness on the surface from two directions (collected approximately $13 \mathrm{~s}$ apart), such that the resulting surface velocity components can be combined to estimate the horizontal surface current vector. In a manner analogous to the low-pass filtering 
of the marine radar image time series, high-resolution $(6 \mathrm{~m})$ ATI-SAR-derived current vectors were spatially averaged over 120-m windows to suppress the surface wave orbital currents and highlight larger-scale flow structures.

Subsurface data were collected via shipborne transects and a moored tripod. Aboard the vessel was a downlooking ADCP, and a weighted CTD was lowered and raised via winch from the aft quarter of the boat. ADCP-derived horizontal velocities and CTD-derived salinity and temperature were interpolated to a common grid with $20-\mathrm{cm}$ vertical spacing and horizontal spacing corresponding to CTD casts (nominally $100 \mathrm{~m}$ ). We present two longitudinal transects of the Columbia River mouth during the second ebb of 12 June 2013, each of which transected a sharp internal interface gradient near a lateral constriction. The first sharp interfacial gradient was transected at 1350 UTC (Fig. 3, blue square) near the Jetty A constriction, and the second sharp interfacial gradient was transected at 1550 UTC (Fig. 3, red square) near the North Jetty constriction. The sharp gradient adjacent to the North Jetty is denoted $\mathrm{J} 1$ (jump 1) and the sharp gradient near Jetty A is denoted J2 (jump 2) hereafter, where the jump number increases in the landward $(+x)$ direction. Although no marine radar data were collected the day that the transects were performed, the consistency between data collected at the same tidal phase one day apart suggests that the shipboard and radar data can be regarded as quasi simultaneous. Indeed, near-surface flow speeds do not vary substantially from 11 to 12 June 2013 (Fig. 3). Attached to the moored tripod, located at $(x, y)=(558 \mathrm{~m},-381 \mathrm{~m})$, was an ADCP (0.5-m bins) and a CTD (one on the tripod and one attached to a float near the surface). Density from the shipborne and moored measurements was calculated from salinity and temperature using the International Thermodynamic Equation Of Seawater2010 (TEOS-10; IOC et al. 2010).

\section{Results and discussion}

\section{a. Jump detection and identification}

The oblique, internal, hydraulic jumps appeared as linear features of increased backscatter in the waveaveraged radar images. Their presence was also confirmed by other remote sensors and by in situ measurements. Specifically, the enhanced backscatter intensity is consistent with the amplified surface roughness expected from the sharp surface velocity convergence observed via ATI-SAR. In situ observations also indicate a thickening of the upper layer in stratified flow. As shown schematically in Fig. 2, the upper-layer thickening here corresponds to critical transitions (and surface convergence) in the observed jump-normal direction. These observations are described in further detail below.

\section{1) DETECTION VIA RADAR REMOTE SENSING}

Each oblique, internal, hydraulic jump was identified as a linear, quasi-stationary region of enhanced backscatter intensity adjacent to a lateral channel constriction in wave-averaged marine radar images during ebb. Six such images showing the evolution of these features (labeled $\mathrm{J} 1$ and $\mathrm{J} 2$ ) during a single ebb are presented in Fig. 4, and a corresponding movie is available online as supplemental material. For spatial context, note that jetties and other solid structures (e.g., navigation buoys and vessels) appear in the image as locations of high backscatter intensity as well. The frontlike structures on the water surface can be characterized by curves of high backscatter intensity, which extend obliquely in a northeast-to-southwest orientation and remain geographically quasi stationary. The upstream (northeast) edge of $\mathrm{J} 1$ was consistently located near the North Jetty, and the upstream edge of $\mathrm{J} 2$ was consistently located near Jetty A, indicating that the features are associated with boundary disturbances.

Other brightly backscattering frontal features are also present in the image time series in Fig. 4. Initial expansion of the ebb plume front head, located in Fig. 4a immediately offshore of the North Jetty, is present in Figs. 4a-d. The northern, lateral boundary of the ebb plume, shown attached to the tip of the North Jetty in Figs. $4 \mathrm{a}-\mathrm{c}$, was observed to propagate northward at $0.2-$ $0.25 \mathrm{~m} \mathrm{~s}^{-1}$ along the coast in Figs. $4 \mathrm{~d}-\mathrm{f}$. The separation of these two plume boundary fronts in Figs. $4 \mathrm{a}$ and $4 \mathrm{~b}$ and the persistently curved horizontal structure where the two would otherwise intersect are suggestive of an anticyclonic "starting jet vortex" (Nicolau del Roure et al. 2009). An additional front, located at $(x, y)=$ $(1 \mathrm{~km}, 1 \mathrm{~km})$ in Fig. $4 \mathrm{a}$, was observed to move toward the North Jetty at an average speed of $0.22 \mathrm{~m} \mathrm{~s}^{-1}$ between the times of Figs. 4a and 4c. This front appeared to reflect off the North Jetty, shown in Fig. 4c, and eventually reached a quasi-stable position to form $\mathrm{J} 1$ (Figs. $4 \mathrm{~d}-\mathrm{f}$ ). Between $\mathrm{J} 1$ and the North Jetty in Figs. $4 \mathrm{~d}-\mathrm{f}$ is a region with lines of alternating bright and dark intensity (black/ white arrow in Fig. 4e), oriented perpendicular to the jetty and J1. These features appear to be instabilities and were observed to move along the jump. The images of $\mathrm{J} 2$ in Figs. $4 \mathrm{a}-\mathrm{f}$ and the images of J1 in Figs. $4 \mathrm{~d}-\mathrm{f}$ show the respective quasi-equilibrium states and the subject of subsequent focus of this paper. Other marine radar images of $\mathrm{J} 2$ (not shown) indicate the presence of an internal wave train, suggesting that at times the jump is dispersive. Temporal evolution of the jumps in this quasi-equilibrium state is discussed later in section $4 \mathrm{~b}$. 

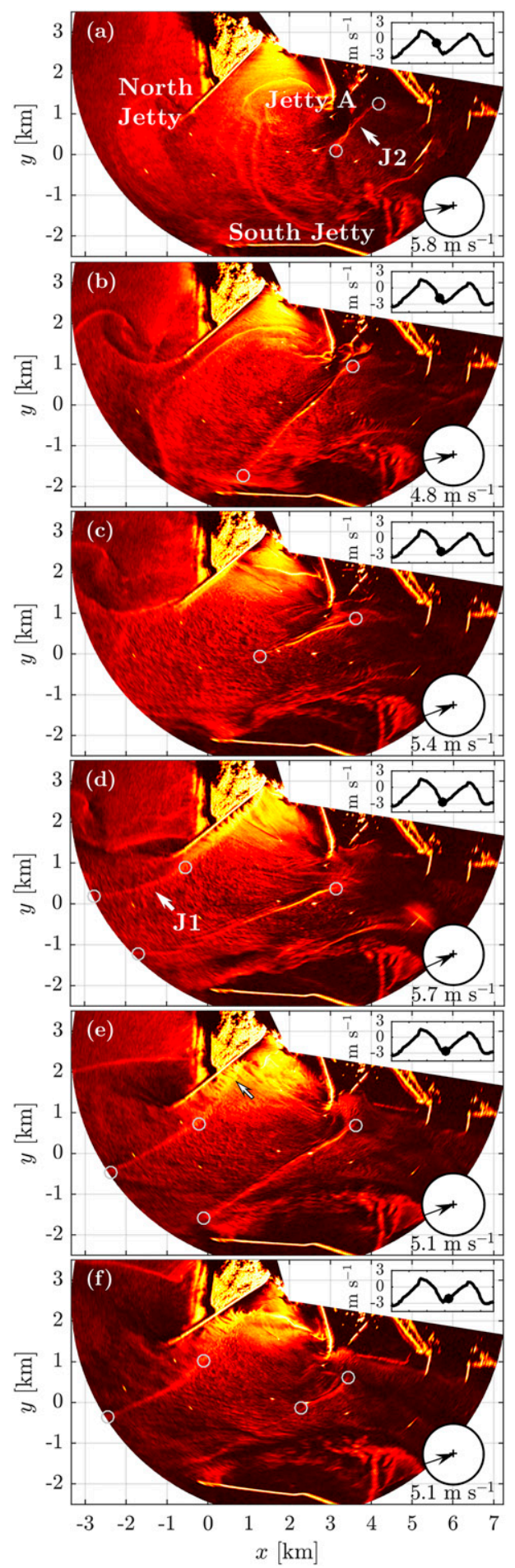

FIG. 4. Image time series of wave-averaged X-band marine radar backscatter intensity on 30 May 2013: (a) 0231, (b) 0320, (c) 0349, (d) 0415, (e) 0512, and (f) 0554 UTC. Jumps J1 and J2 are labeled with white arrows in (d) and (a), respectively, and moving instabilities (black and white arrow, no label) are labeled in (e). Gray circles mark approximate end points of each jump. (top insets) Along-channel current at tripod and (bottom insets) wind speed and direction at station 3CLO3 (see Fig. 1). The full radar image time series (movie) spanning 0115 UTC to 0754 UTC is available online as supplemental material.
Although a variety of environmental processes can cause spatial modulations in microwave backscatter intensity (e.g., wind field inhomogeneity), strong surface convergence observed via the ATI-SAR along J1 (Fig. 5) is consistent with the current gradient imaging mechanism. The locally amplified convergence $-(\partial u / \partial x+\partial v / \partial y)$ reaches $2 \times 10^{-3}$ to $4 \times 10^{-3} \mathrm{~m} \mathrm{~s}^{-1}$ along the length of the high backscatter feature; surface current gradients of this magnitude have been observed previously with enhanced microwave backscatter (via SAR) across convergent density fronts (e.g., Marmorino et al. 1998). A second region of convergent flow and high backscatter is present at $(x, y)=(-1.75 \mathrm{~km}, 1.25 \mathrm{~km})$ and is attributed to the ebb plume front.

The alongfront component of the velocity gradient has often been neglected in the analysis of enhanced backscatter, so for a direct comparison with previous findings we report that cross-jump deceleration of the surface current exceeds $8.8 \times 10^{-3} \mathrm{~s}^{-1}\left(88 \mathrm{~cm} \mathrm{~s}^{-1}\right.$ over $100 \mathrm{~m})$. This strong, cross-front component of the current gradient is in the range of those previously observed (e.g., Marmorino et al. 1998) and causes a sharp, southward deflection of the ebbing flow that is consistent with an upper-layer, oblique internal hydraulic jump. Since the component of incident flow aligned along the jump is unaffected by the dominant, cross-jump momentum balance, deceleration of only the cross-jump component then results in a rotation of the total current vector in the direction of the incident along-jump flow.

\section{2) SHIPBORNE TRANSECTS}

Subsurface velocity and density transects confirm the presence of a rapid thickening of the upper layer at each jump and demonstrate that it corresponds to an internally supercritical-to-subcritical transition at both $\mathrm{J} 1$ and J2. The jumps can each be identified by a sharp depression in isopycnals (Figs. 6a and 7a), falling as much as half the water column between successive CTD casts (spaced $\sim 100 \mathrm{~m}$ apart). Interpolated to coincide with the CTD casts for subsequent calculations, sharp horizontal velocity gradients in both the along- and cross-channel directions (Figs. 6b,c, 7b,c) accompany these horizontal density gradients. Acoustic backscatter (ABS) intensity from the shipborne ADCP at $8.5-\mathrm{m}$ horizontal spacing (Fig. 2c) additionally reveals the undular structure of $\mathbf{J} 2$; surface waves caused the vessel to heave, resulting in the high-frequency horizontal variability visible throughout the water column (including the strong return from the bottom boundary). The acoustic backscatter signature from J1, not shown, was less clear.

A two-layer approximation is utilized to characterize the flow, motivated by locally elevated levels of the buoyancy frequency $N^{2}=-(g / \rho)(\partial \rho / \partial z)$ (Figs. 6d, 7d). 

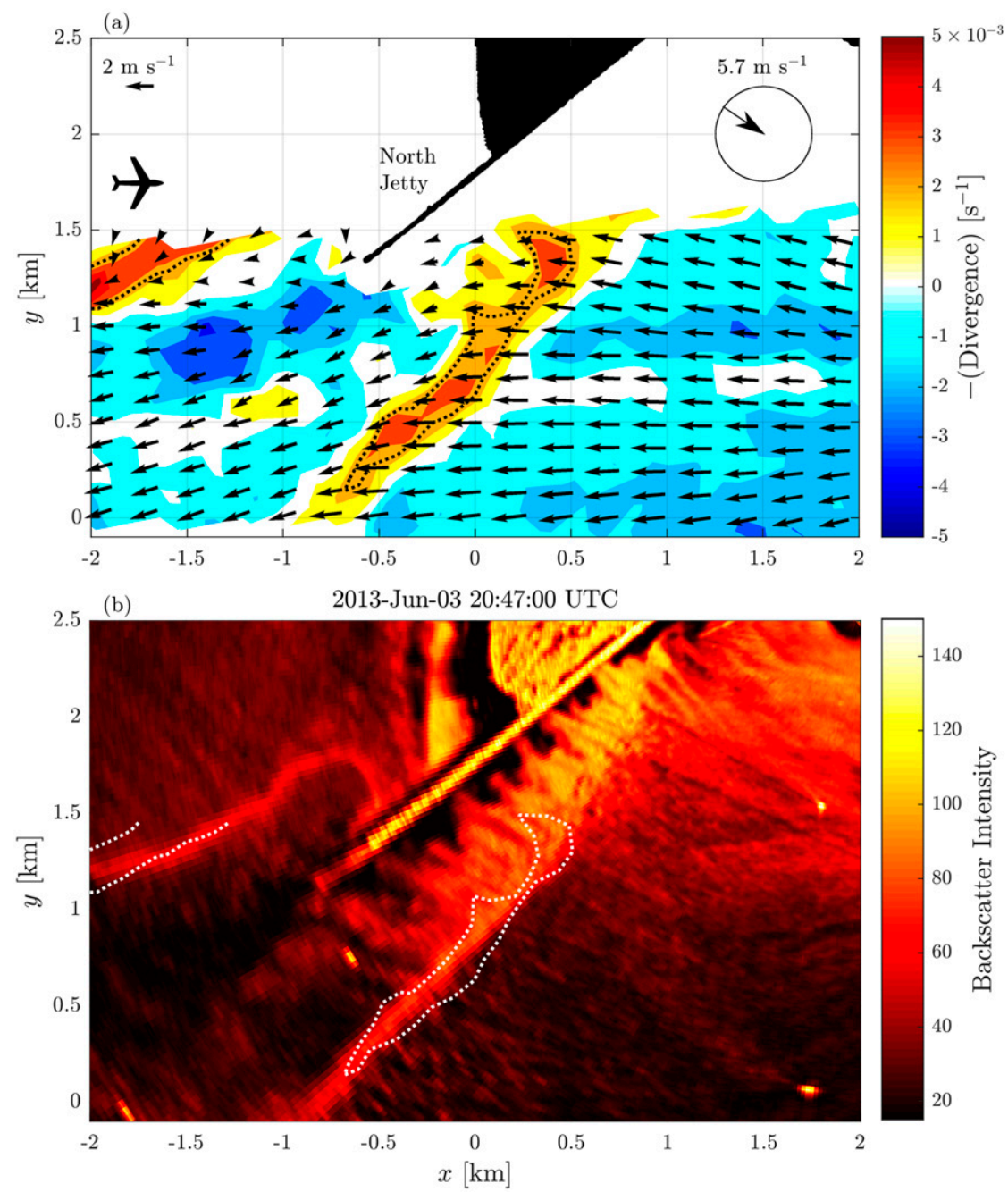

FIG. 5. (a) ATI-SAR-derived surface current vectors overlaid on negative surface divergence. Surface current scale vector and flight direction are shown in the upper left, and wind direction and speed are inset in the upper right. (b) Corresponding wave-averaged marine radar image with $\mathrm{J} 1$ clearly visible. The overlapping coverage also includes the northern boundary of the convergent ebb plume front at $(x, y)=(-1.75 \mathrm{~km}, 1.2 \mathrm{~km})$. The $2.5 \times 10^{-3} \mathrm{~s}^{-1}$ contour of negative divergence is shown as a dotted line in each panel; note that ATI-SAR data were acquired over 20 vs $1.3 \mathrm{~min}$ for the marine radar.

The $\rho=1012 \mathrm{~kg} \mathrm{~m}^{-3}$ isopycnal (see Figs. 6, 7, red dashed line) is used to represent the interface, as it corresponds best to the vertical location of maximum stratification throughout each transect. Other methods of defining the interface depth, including the horizontally resolved vertical location of maximum stratification and a least squares hyperbolic tangent fit to the density profile, add scatter to the computed quantities. Despite this scatter, varying the interface depth definition was not found to alter the conclusions of this work. Representative layer densities and velocities were defined as the layer means; however, because of the presence of some vertical shear in the individual layers (Figs. 6e, 7e), additional precision was obtained by multiplying the layer Froude numbers $\mathrm{Fr}_{i}$ by the corresponding energy distribution coefficient formulated using a linear fit to the vertical velocity profile of each layer (e.g., Chow 1959). The energy distribution coefficient corrects the inertial term in the Froude number of each layer by accounting for a nonuniform velocity profile. The reduced gravitational acceleration remained relatively constant along the transects: $\bar{g}^{\prime}=0.13 \pm$ $0.01 \mathrm{~m} \mathrm{~s}^{-1}$ across $\mathrm{J} 1$ and $\bar{g}^{\prime}=0.15 \pm 0.01 \mathrm{~m} \mathrm{~s}^{-1}$ across $\mathrm{J} 2$.

As shown in Figs. $6 \mathrm{f}$ and $7 \mathrm{f}$, the ebbing, along-channel flow remains internally supercritical $(G>1)$ through each of the jumps. These oblique hydraulic features therefore do not correspond to locations of streamwise 

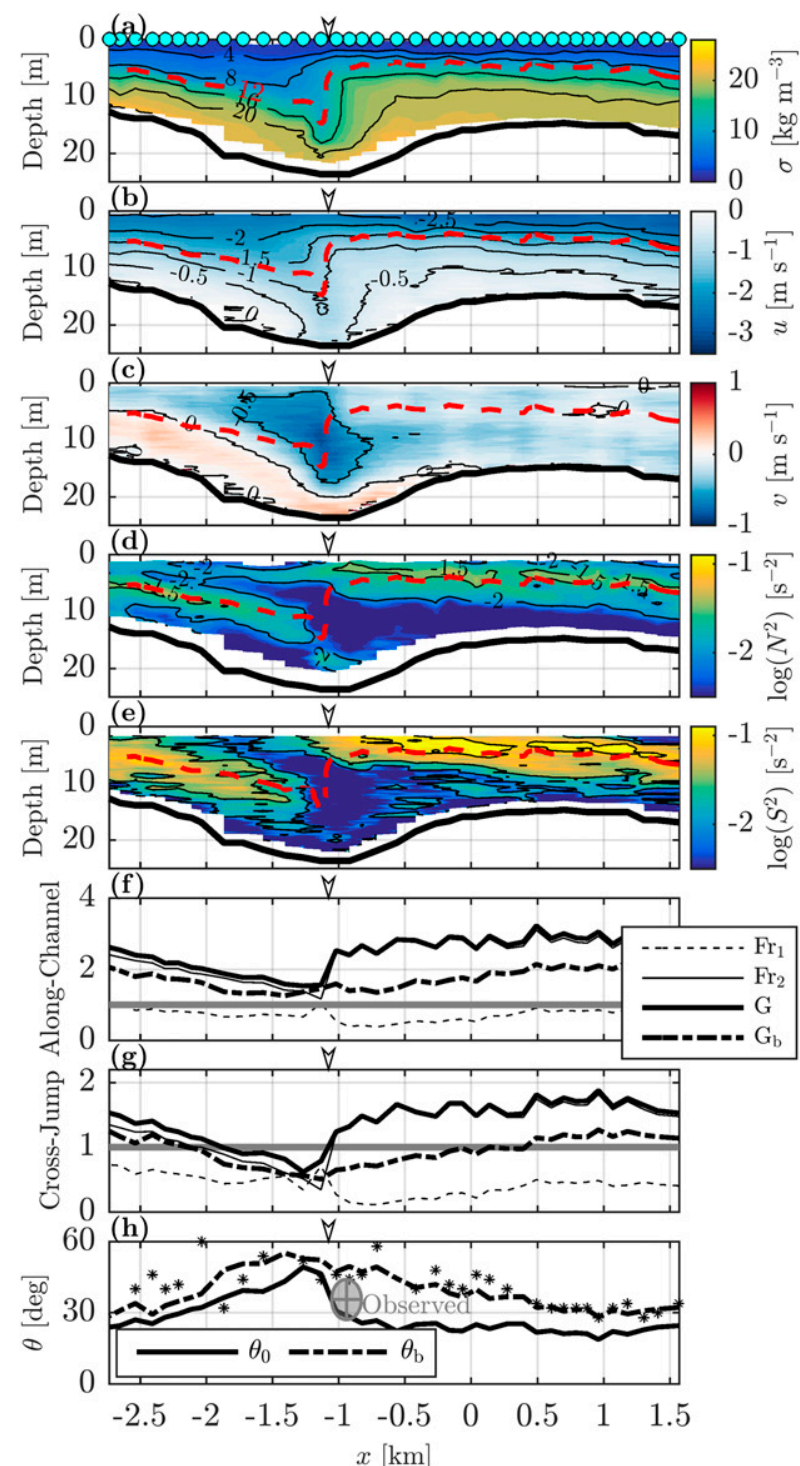

FIG. 6. Shipborne transect data of J1 recorded on 1550 UTC 12 Jun; down-pointing arrows mark the jump location. (a) Contours of the density anomaly $\sigma=\rho-1000$; channel bottom is denoted by a solid black line and locations of CTD casts marked by cyan circles along $z=0$. Interface for two-layer approximation $\rho=1012 \mathrm{~kg} \mathrm{~m}^{-3}$ is denoted by the red dashed line. (b) East-west (along channel) velocity contours. (c) North-south (cross channel) velocity contours. (d) Buoyancy frequency. (e) Squared vertical shear of alongchannel flow $S^{2}=(\partial u / \partial x)^{2}$. (f) Along-channel Froude numbers with unity in gray for reference. (g) Cross-channel Froude numbers with unity in gray for reference [see (f) for legend]. (h) Estimated two-layer (lines), estimated vertically resolved (stars), and observed (gray ellipse) jump angles.

hydraulic control. However, as the transects in Figs. 6 and 7 show, they do affect internal flow properties (e.g., pycnocline depth and active layer velocity) that may affect downstream streamwise hydraulics not locked to bottom or lateral boundary extrema.
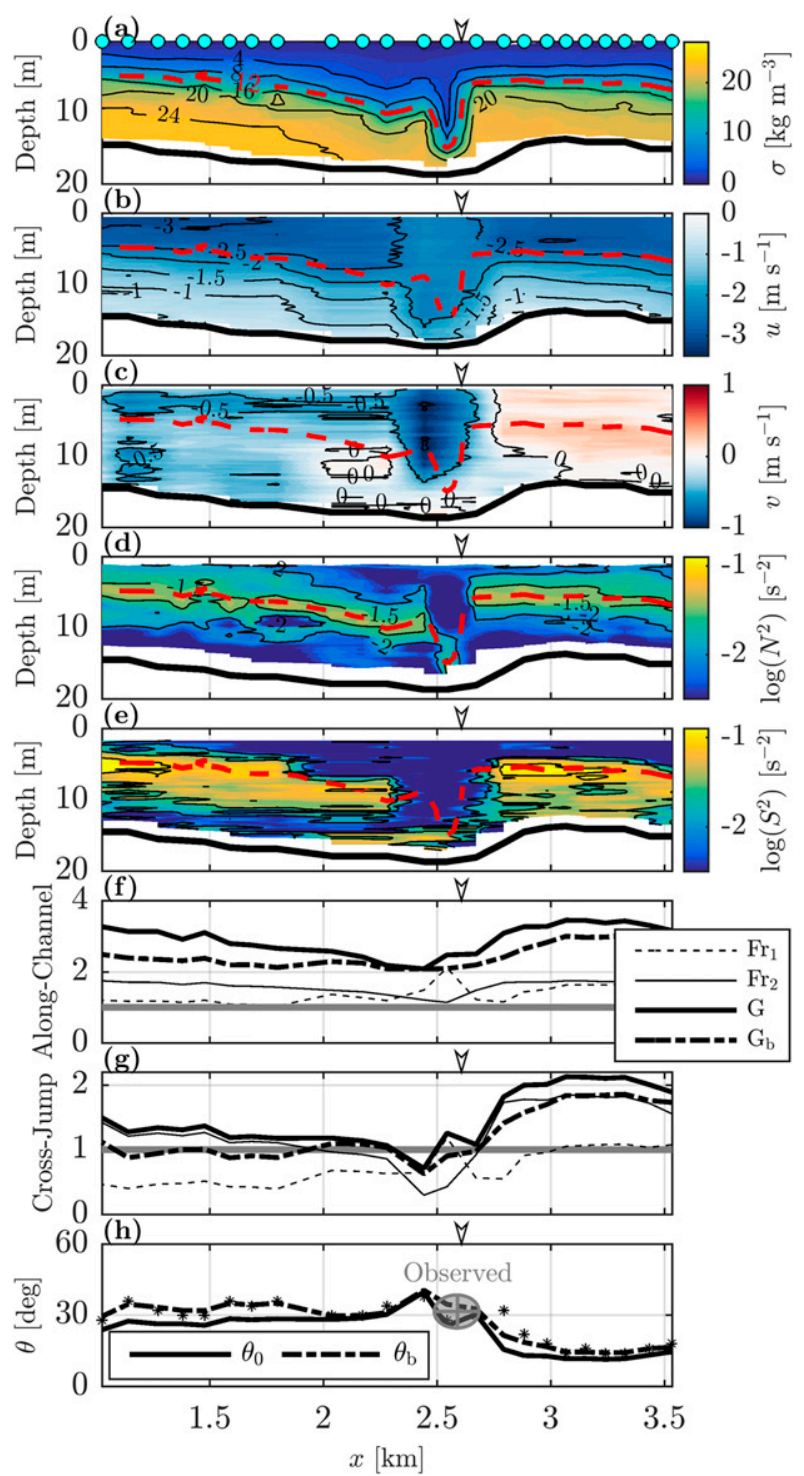

FIG. 7. As in Fig. 6, but transect data of J2 from 1350 UTC 12 Jun.

The cross-jump component of the flow does transition from supercritical to subcritical (Figs. $6 \mathrm{~g}, 7 \mathrm{~g}$ ) for both $\mathrm{J} 1$ and $\mathrm{J} 2$, satisfying the necessary condition for the presence of a hydraulic jump. Here, the cross-jump direction was defined using the jump angle derived from a marine radar image collected the day prior to the transects but at the same tidal phase (see appendix). It is of note that the upper-layer Froude number dominates the lower layer $\left(\mathrm{Fr}_{2}>\mathrm{Fr}_{1}\right)$. For J1, the upstream cross-jump $\mathrm{Fr}_{2}$ and $G$ lines are indistinguishable; such upper-layer dominance is consistent with our interpretation that this jump is an upper-layer jump. A brief period of increased lower-layer Froude number at each jump $(x=-1.2 \mathrm{~km}$ for $\mathrm{J} 1$ and $x=2.55 \mathrm{~km}$ for $\mathrm{J} 2)$ corresponds to the nonhydrostatic, large-amplitude "head" of the 
jumps, which vertically constricts and advectively accelerates the lower-layer flow. The large amplitude of the heads at J1 and J2 suggest that, despite upper-layer dominance, depth variations may still play a role in disturbance celerity. Depth contours in Fig. 1 show that the jumps extend over moderate slopes, yet because alongfront variability is neglected here, increasing model complexity by calculating nonlinear internal bore celerities using depth-resolved stratification does not necessarily coincide with additional accuracy. We note that a large-amplitude head can occur for even relatively small jumps in the presence of upstream shear (Klemp et al. 1997; Ogden and Helfrich 2016), as is the case for $\mathrm{J} 1$ and $\mathrm{J} 2$.

The observed jump angles lie within the expected bounds described in section $2\left(\theta_{0}<\theta<\theta_{b}\right)$. Figures $6 \mathrm{~h}$ and $7 \mathrm{~h}$ show the critical angles for the long-wave [Eq. (2)] and maximum-amplitude bore [Eq. (5)] along the J1 and $\mathrm{J} 2$ transects, calculated from the transect measurements. Located between the two bounds for each transect is the observed angle (with respect to the westerly, along-channel flow in each case), including an estimate of uncertainty in angle and along-channel position.

Although some effects of finite interface thickness and upstream vertical shear on the internal bore speed have recently been documented (White and Helfrich 2014; Ogden and Helfrich 2016), details of a combination of the two remain poorly understood. The Taylor-Goldstein equation (e.g., Miles 1961) resolves such continuous vertical structure, and estimated jump angles corresponding to normal-mode phase speed solutions of the equation (Kundu and Cohen 2004; Smyth et al. 2011) are shown in Figs. $6 \mathrm{~h}$ and $7 \mathrm{~h}$. Some erratic behavior is present in the vicinity of $\mathrm{J} 1$, in part due to solution sensitivity to variability in near-bottom velocity and nonuniform crosschannel flow structure. Nevertheless, these estimates are dominantly similar to those both derived from two-layer theory as well as those observed via radar.

\section{b. Jump recurrence and evolution}

Many realizations of both jumps were possible due to the long dwell nature of the shore-based radar, revealing that the upchannel jump (J2) recurred each ebb and that the downchannel jump (J1) was not present only during the largest-amplitude ebbs. As stratification and ebbing flow varied throughout each ebb, so did the angle of each jump. Trends in these jump angles were largely consistent with those expected from corresponding trends in flow properties measured at the tripod (see Fig. 1); a deviation from this correspondence is consistent with the presence of bathymetric influence. Sampled over a range of tidal amplitudes and freshwater discharge conditions, intertidal variability in the intratidal evolution of J1 appears to be associated with current speed and stratification. In contrast, remarkably little intertidal variability was observed in the intratidal evolution of $\mathrm{J} 2$.

\section{1) Tidal ReCurRence}

The jumps were observed to occur during ebb, with some variability between $\mathrm{J} 1$ and $\mathrm{J} 2$ in tidal recurrence. Cataloged visual detection of both jumps between 24 May and 11 June, shown in Fig. 3, demonstrates that $\mathrm{J} 2$ recurs consistently but $\mathrm{J} 1$ does not. The only ebbs during which $\mathrm{J} 2$ was not observed are those that were not fully sampled by the radar (including 30 May and 46 June). Although J1 was observed during most of the sampled ebbs, there is a notable absence of $\mathrm{J} 1$ detections during the major, spring ebbs during 24-29 May. Phaseaveraged density and along-channel vertical shear time series at the tripod during these strong ebbs (Figs. 8b,c) exhibit decreased stratification as well as a deeper and broader shear layer as compared to those ebbs for which J1 was detected (Figs. 8d,e). We therefore hypothesize that $\mathrm{J} 1$ was not detected in the radar imagery during the observation period (24 May-11 June) as a result of one or both of the following processes: (i) the stronger upper-layer flow, lower stratification, and broader pycnocline all contribute to a supercritical hydraulic state beyond that which can stably transition to a subcritical state, and (ii) the lower pycnocline decreases the maximum jump amplitude, thereby decreasing the surface convergence below a level detectable by the radar. Unfortunately, the cross-channel separation of $\mathrm{J} 1$ and the tripod does not allow for testing of these hypotheses.

The phase-averaged surface and bottom density time series during the ebbs that $\mathrm{J} 1$ was not detected are shown in Fig. 8b. This mean condition is representative of the individual ebbs: density differences of $0.5-2 \mathrm{~kg} \mathrm{~m}^{-3}$ or less persisted from 3 to about $6.5 \mathrm{~h}$ after high tide, inclusive of when $\mathrm{J} 1$ detections were most common. The vertical location of maximum shear, a proxy for interface depth when vertically resolved density information is not available, is relatively low in the water column (or not clearly present) in similarly phaseaveraged shear profile time series (Fig. 8c). In contrast, phase-averaged stratification remained stronger throughout the ebbs during which $\mathrm{J} 1$ was detected (Fig. 8d), and a shear layer is clearly present in the midto upper-water column (Fig. 8e). Assuming that a similar trend was present at J1, (i) decreased stratification and a less well-defined shear layer (interface) during the strong ebbs would have resulted in slower internal disturbance speeds, and (ii) a thicker upstream layer decreased the maximum jump amplitude, thereby decreasing the maximum cross-jump surface convergence. The tripod data then suggest that either the 

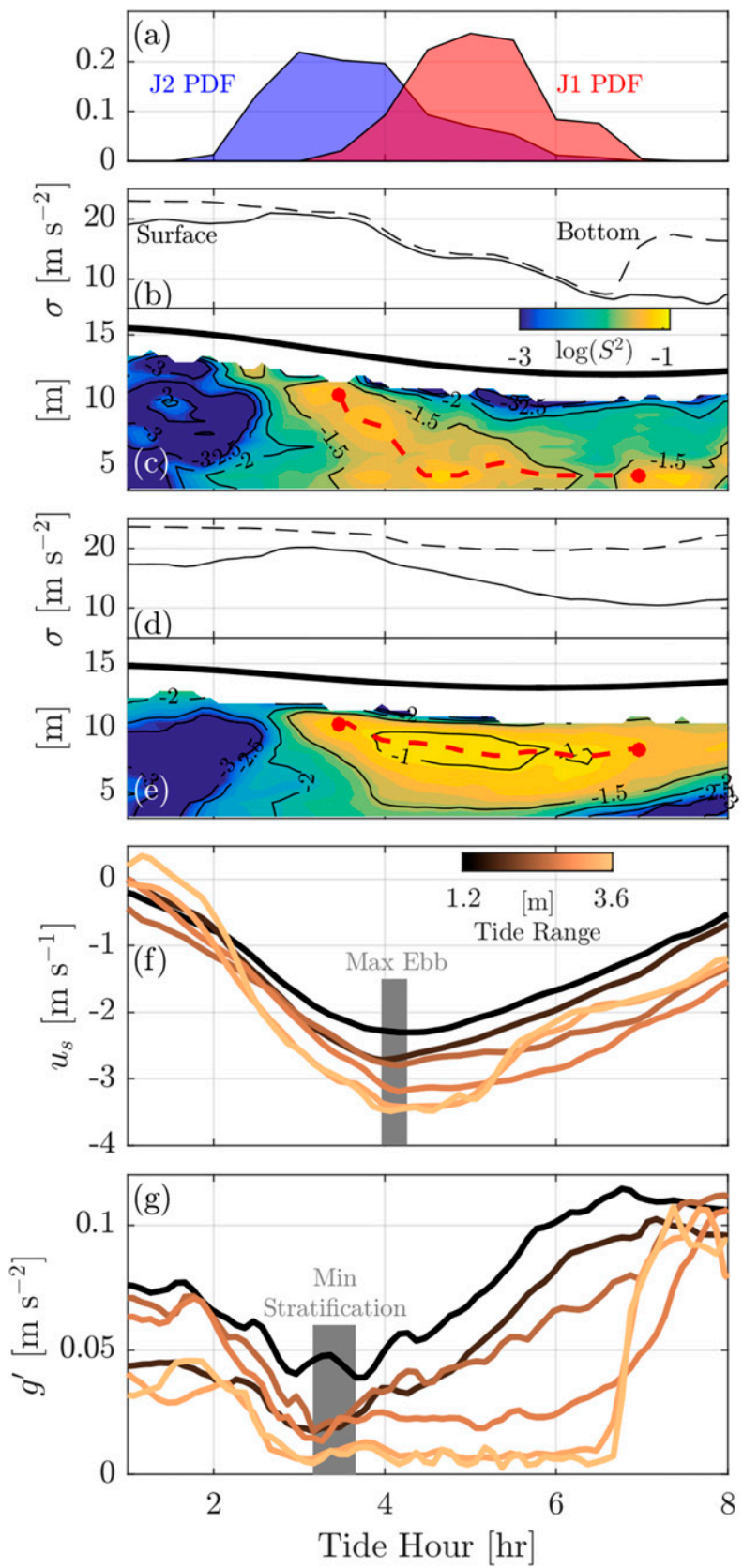

FIG. 8. Jump occurrence and in situ conditions as a function of hour after high tide. (a) Probability density functions of jump occurrence. (b) Mean bottom (dashed line) and surface (solid line) density conditions while $\mathrm{J} 1$ was not detected. (c) Mean $S^{2}$ conditions and location of shear maximum (red dashed line) while $\mathrm{J} 1$ was not detected. (d) Mean bottom (dashed line) and surface (solid line) density conditions while J1 was detected. (e) Mean $S^{2}$ conditions and location of shear maximum (red dashed line) while $\mathrm{J} 1$ was detected. (f) $u_{s}$ time series, bin averaged by tide range with bin centers at 1.25 , $1.5, \ldots$, and $3.5 \mathrm{~m}$ (also see color bar). (g) $g^{\prime}$ time series, also bin averaged by tide range (tide range indicated by color). weakened pycnocline could not support a stable J1 during the strong ebbs or that corresponding surface convergence was substantially weaker due to a smaller possible jump amplitude. The presence of $\mathrm{J} 2$ during these periods, however, indicates that additional factors and/or variability may be present that affect jump visibility.

It is unlikely that lack of jump detection in the radar images was due to wind conditions because jumps were observed during winds from all directions and with speeds between 0 and $11.3 \mathrm{~m} \mathrm{~s}^{-1}$ based on 15 -min average winds measured on the south shore of the river mouth (station 3CLO3; see Fig. 1).

\section{2) INTRATIDAL EVOLUTION}

Observed angles, shown as a function of time after the previous high tide in Fig. 9, exhibit variability on time scales ranging from the sampling time step of $1 \mathrm{~min}$ to the interseasonal levels of freshwater discharge. The aggregate observations, with the aid of median filters (blue and red lines) for the high discharge period, reveal common progressions of $\theta$. After a short period of increasing obliquity (decreasing theta) to the flow following onset of $\mathrm{J} 1, \theta$ corresponding to $\mathrm{J} 1$ increases monotonically (Fig. 9a); J2, which appeared $1.5 \mathrm{~h}$ before $\mathrm{J} 1 \mathrm{on}$ average, typically first exhibited a decrease in $\theta$ over the course of $1 \mathrm{~h}$ before increasing and achieving a stable angle (Fig. 9c). Phases of the tide that correspond to representative values of $\theta$ are labeled T1-T4 in Figs. 9a and 9c, and the jump positions that correspond to $\mathrm{J} 1$ and $\mathrm{J} 2$ at times T1-T4 are shown in Fig. 10.

As outlined in section 2, changes in $\theta$ can correspond to variability of the incident fluid properties (e.g., $g^{\prime}$ and flow speed), variability of the bore amplitude, or both. After the rapid adjustment to a quasi-stationary state subsequent to frontal reflection off the North Jetty, the aforementioned angle evolution of $\mathrm{J} 1$ is consistent with changes of incident flow at the tripod; increasing $g^{\prime}$ and decreasing near-surface current speed $u_{s}$ work together to decrease the incident flow Froude number and therefore an increase in $\theta$. Note that although a more direct comparison of angles (via estimation of $\mathrm{Fr}_{i}$ ) at the tripod is possible, such a comparison between separate streamlines can be spuriously precise due to compounded uncertainty of the calculated quantities.

The tripod-based measurements concurrent to J2 observations during the high discharge period suggests that the factors governing the angle evolution of $\mathrm{J} 2$ may be more complex (Fig. 9c). Again, relative changes in $g^{\prime}$ and $u_{s}$ at the tripod are expected to be more reliably representative of incident $\mathrm{J} 2$ conditions than quantities that rely on estimation of the interface depth. From time T1 to T3, changes in the angle evolution are also consistent with corresponding changes in stratification and 

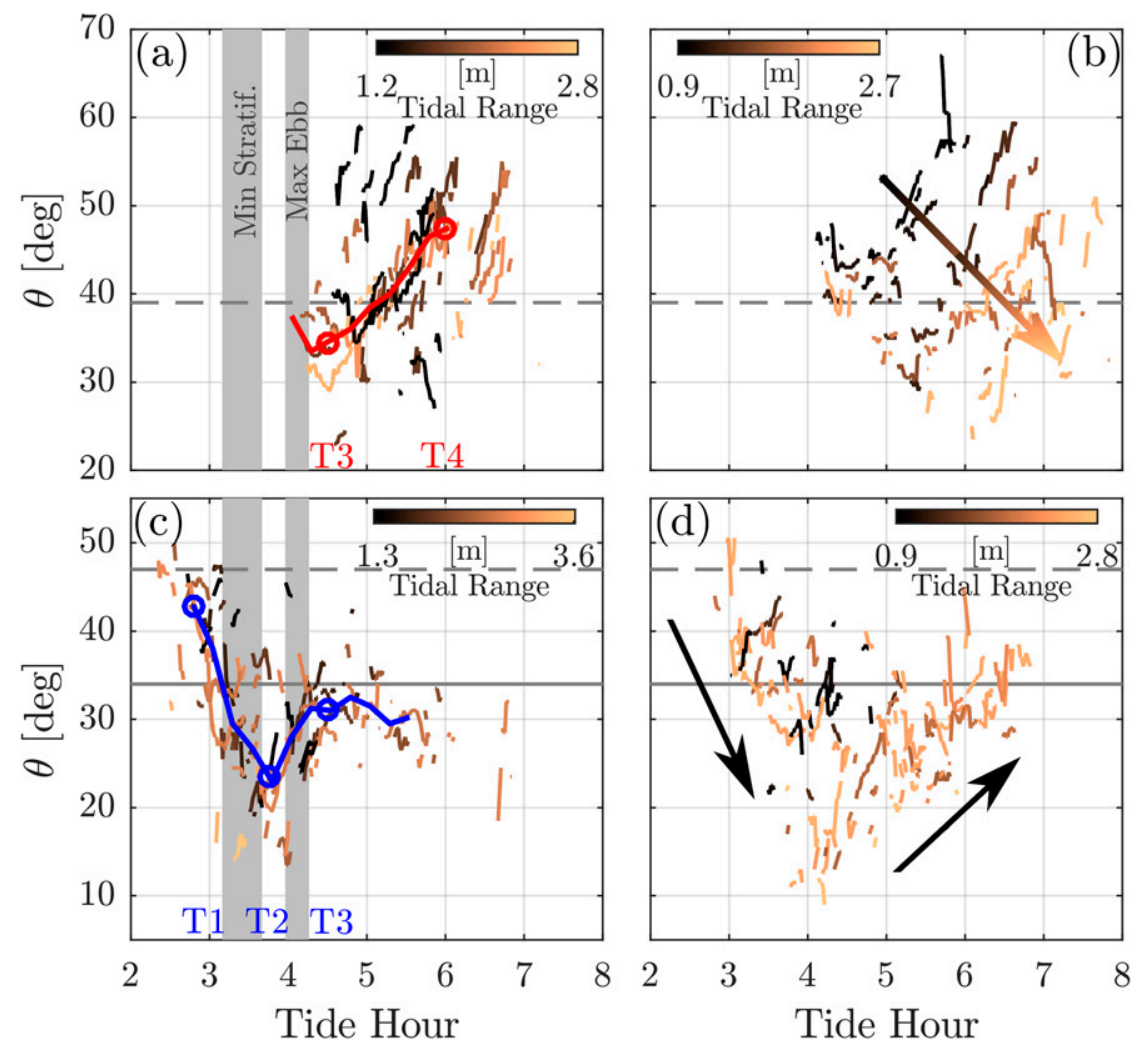

FIG. 9. Phase-averaged time series of observed jump angle $\theta$ and median-filtered values are shown as solid curves in red and blue: (top) J1 and (bottom) J2. (a),(c) High discharge and (b),(d) low discharge. Tidal hour (phase) of minimum stratification and maximum ebb during high discharge are shown as vertical gray bars (corresponding to those in Figs. 8c and 8d). Relevant angles of lateral boundaries (dashed lines): North Jetty in (a) and (b) and pile dikes near Jetty A in (c) and (d). Relevant angle of bottom boundary (solid lines): oblique bathymetric gradient in (c) and (d). For low discharge conditions, the gradient color arrow in (b) follows the intertidal trend and black arrows in (d) follow the intratidal trend.

active layer flow. Decreasing $\theta$ corresponds to decreasing $g^{\prime}$ and increasing active layer flow from $\mathrm{T} 1$ to the stratification minimum, increasing $\theta$ corresponds to increasing $g^{\prime}$ and decreasing active layer flow from the ebb maximum to T3, and the $\theta$ minimum (at T2) occurs during a period of balance between the stratification minimum and the ebb maximum. Despite continued increase in $g^{\prime}$ and decrease in $u_{s}$ after T3, $\theta$ remains steady in the vicinity of $30^{\circ}$ until no longer detected in the radar images. This relatively stable angle coincides with the angle of a similarly oblique bathymetric slope, also shown and labeled in Fig. 10, that extends southwest from a depth maximum adjacent to Jetty A.

The apparent difficulty of the jump in moving past this bathymetric feature is consistent with the presence of bottom boundary influence. This influence can arise from lower-layer contribution to the Froude number. Changes in total depth where $\mathrm{Fr}_{1} \approx 0$ are uncoupled from upperlayer dynamics, but where $\mathrm{Fr}_{1}$ is finite, total depth changes can substantially affect spatial variations of $G$ (e.g., Armi 1986). Finite-amplitude effects intensify this dependence of the upper-layer bore speed on the total depth up to the limiting case of the conjugate state [see Eq. (5)]. Observed transcritical values of cross-jump $\mathrm{Fr}_{1}$ upstream of $\mathrm{J} 2$ (Fig. $7 \mathrm{~g}$ ) indicate that bottom boundary influence is possible. Subsurface observations of J2 between times T3 and $\mathrm{T} 4$ are required to confirm this hypothesis; if true, a feedback mechanism involving the scour beneath the jump head and the arrest location of the jump may be present.

\section{3) INTERTIDAL AND INTERSEASONAL VARIABILITY}

Figure 9 shows that intertidal variability was more pronounced at $\mathrm{J} 1$ and during low river discharge (September) than at $\mathbf{J} 2$ and during the freshet (May-June), while the intratidal trend for each jump remained similar between the two discharge levels. Ebb tidal range 


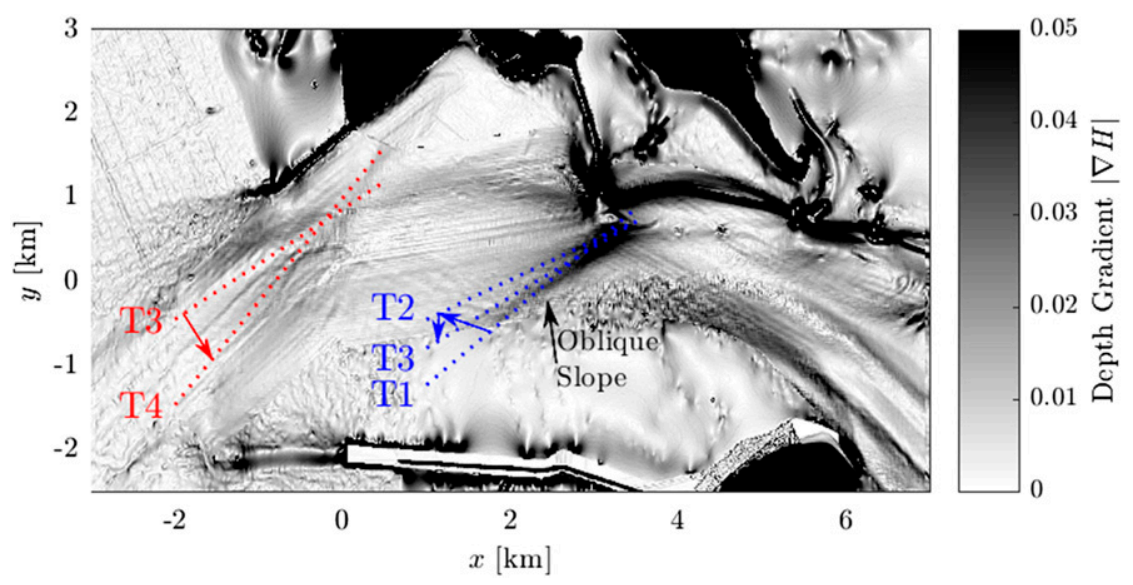

FIG. 10. Example (median) orientations of $\mathrm{J} 1$ and $\mathrm{J} 2$ corresponding to labeled times $\mathrm{T} 1-\mathrm{T} 4$ (high discharge) in Fig. 9 on total depth gradient $|\nabla H(x, y)|$. Colored arrows follow the temporal trend of median $\mathbf{J} 1$ and $\mathbf{J} 2$ orientations. Bathymetry data are a merged product using a NOAA NGDC tsunami inundation map and a USGS SwathPlus multibeam survey (Gelfenbaum et al. 2015). The angle of the oblique slope (labeled) corresponds to the solid horizontal line in Figs. 9c and 9d.

indicates the relative level of barotropic forcing between tides; increased barotropic forcing indicates stronger ebb flow and increased shear, enhancing vertical mixing and decreasing stratification. This can be seen at the tripod (Figs. 8f,g). Larger tidal ranges correspond to stronger flow and weaker stratification during maximum ebb. These stronger flows and lower levels of stratification, indicators of increasingly supercritical flow, were also observed to penetrate later into the larger ebbs, suggesting that lower jump angles may occur during, and penetrate later into, the larger ebbs. J1 appears to show some ordering with tidal range that is consistent with this trend despite some clustering about the median. However, during the high discharge conditions, no discernible trend in jump angle with tide range is present for J2 (Fig. 9c).

An ordering with tidal range, consistent with jump angle variability with incident flow conditions, is significantly more clear at $\mathrm{J} 1$ during low discharge conditions (see color gradient arrow; Fig. 9b). Because the tripod was not deployed during this period, no subsurface measurements were available to directly inform jump angle evolution. We estimate that the lowered buoyancy input during periods of lesser river discharge allow low levels of stratification to persist later into the ebb than during high discharge conditions. This effectively amplifies the trend with tide range in Fig. 8g. Since both J1 and $\mathrm{J} 2$ were observed during this period (Figs. 9b,d), we infer that weaker ebb flows balanced weaker stratification to maintain a jump-supporting pycnocline. No clear trend in jump angle with tidal range is apparent for $\mathrm{J} 2$ during the low discharge period (Fig. 9d), and intratidal trends in jump angle remained similar between the two discharge conditions. J2 exhibited first a decrease in angle followed by an increase (see black arrows; Fig. 9d), and $\mathrm{J} 1$, again appearing later in the ebb, exhibited a monotonic increase in angle (Fig. 9d).

\section{Conclusions}

Two oblique, internal hydraulic jumps were identified and analyzed using a suite of remote sensing and in situ observations at the Columbia River Mouth. The internal jumps were detected by the presence of locally enhanced microwave backscatter in temporally filtered $\mathrm{X}$-band marine radar imagery and verified by the presence of an internal critical transition from supercritical to subcritical in the cross-jump direction. The jumps were also detected via a sharp deflection of the surface current field derived from an airborne ATI-SAR overflight, resulting in strong surface convergence. Observed jump angles, calculated via Radon transform of the radar image time series, fell reasonably within estimated lower (arrested long wave) and upper (arrested maximumamplitude bore) bounds derived using a two-layer model.

The upstream jump was observed to recur tidally during ebb, and the downstream jump recurred tidally with the exception of the strongest spring tides. Intratidal evolution of the jump angle trended consistently with that expected from corresponding temporal trends in current speed and stratification; deviation from this trend occurred as the upstream jump approached a bathymetric upslope feature, which in turn is consistent with bottom boundary influence. Despite observed intertidal variability and expected interseasonal variability in current speed and stratification, only the downstream 
jump showed clear signs of association with these important flow parameters. Intratidal trends in angle and position of upstream jump, however, were remarkably consistent in the presence of varied tidal forcing, during both the annual maximum and minimum freshwater discharge months.

Acknowledgments. We acknowledge the financial support of the Office of Naval Research under Awards N00014-10-1-0932 and N00014-13-1-0364. Guillermo Díaz Méndez and Randall Pittman secured the flow of marine radar data, and Peter Traykovski generously provided tripod data. We thank the U.S. Coast Guard at Cape Disappointment for continuing to generously host the radar observation station. The authors also acknowledge constructive discussions of these observations with Chris Chickadel, Craig McNeil, Jim Thomson, and Roger Samelson. Two anonymous reviewers provided helpful feedback in the writing of this manuscript. Data are available upon request of the authors.

\section{APPENDIX}

\section{Calculation of Jump Angles}

Hydraulic jump angles in the backscatter intensity images are quantified by locating and modeling Radon transform peaks. Variants of this method have been implemented for the detection and quantification of internal wave signatures in marine radar imagery (Chang et al. 2008; Ramos et al. 2009; Nelson 2009). The Radon transform computes line integrals of pixel intensity, varying with distance from the image center and angle from the horizontal axis:

$$
R(\theta, x)=\int_{-\infty}^{\infty} I\left(x^{\prime} \cos \theta-y^{\prime} \sin \theta, x^{\prime} \sin \theta+y^{\prime} \cos \theta\right) d y^{\prime},
$$

where $R$ is the Radon-transformed image intensity, $I$ is the original backscatter image intensity, and $x^{\prime}, y^{\prime}$ represent Cartesian coordinates after a rotation by the angle $\theta$ :

$$
\left[\begin{array}{l}
x^{\prime} \\
y^{\prime}
\end{array}\right]=\left[\begin{array}{cc}
\cos \theta & \sin \theta \\
-\sin \theta & \cos \theta
\end{array}\right]\left[\begin{array}{l}
x \\
y
\end{array}\right] .
$$

An ideal line in the original image corresponds to a Dirac delta function in Radon space; the curvature and thickness of linear features in the backscatter intensity images correspond to localized peaks of finite breadth in the Radon-transformed image.

After detrending via subtraction of the Radontransformed image of a flat, mean, backscatter
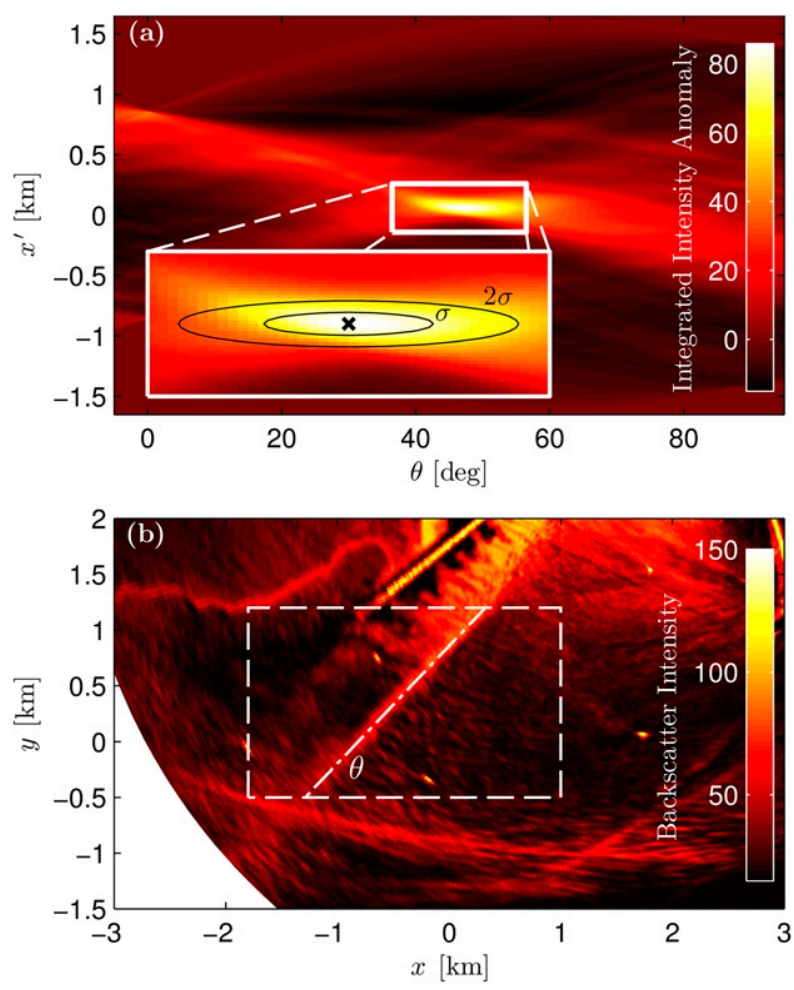

FIG. A1. (a) Detrended Radon-transformed backscatter intensity image. Inset indicates a white rectangle defines the Gaussian surface fitting region. The Radon space intensity peak is marked with a black $\mathrm{X}$ and two modeled Gaussian surface contours (black lines) denote $1 \sigma$ and $2 \sigma$ peak widths. (b) Corresponding marine radar backscatter intensity image (2047 UTC 3 Jun,), Radon transform subimage domain (white dashed box), and resulting estimated angle of obliquity (white dashed-dotted line).

intensity plane, hydraulic jump obliquity was then found by the angle of the Radon image maximum (Fig. A1a, black X). Radon image peaks not associated with the hydraulic jump (e.g., vessel traffic) were eliminated by spatially limiting the images to the region of interest (e.g., Fig. A1b, white dashed box, for the North Jetty jump) and by visual inspection. Uncertainty in angle is quantified by fitting the Radon image peak to a Gaussian surface:

$$
f\left(\theta, x^{\prime}\right)=\alpha \exp \left\{-\left[\frac{\left(x^{\prime}-x_{0}^{\prime}\right)^{2}}{2 \sigma_{x^{\prime}}^{2}}+\frac{\left(\theta-\theta_{0}\right)^{2}}{2 \sigma_{\theta}^{2}}\right]\right\}+\beta,
$$

where the peak location $\theta_{0}, x_{0}^{\prime}$ is constrained to the intensity maximum pixel location, and amplitude $\alpha$, intensity offset $\beta$, and peak widths $\sigma_{x^{\prime}}, \sigma_{\theta}$ are allowed to vary. The surface fit is localized within the Radontransformed domain to $R\left(\theta_{0} \pm 10^{\circ}, x_{0}^{\prime} \pm 200 \mathrm{~m}\right)$ to minimize the contribution of spurious peaks. The Gaussian surface fit region and resulting $\sigma, 2 \sigma$ constant intensity 
contour ellipses are shown in Fig. A1a (inset). Radarobserved jump angles are herein defined as $\theta \pm 2 \sigma_{\theta}$.

\section{REFERENCES}

Akers, B., and O. Bokhove, 2008: Hydraulic flow through a channel contraction: Multiple steady states. Phys. Fluids, 20, 056601, doi:10.1063/1.2909659.

Armi, L., 1986: The hydraulics of two flowing layers with different densities. J. Fluid Mech., 163, 27-58, doi:10.1017/ S0022112086002197.

—_, and G. J. Mayr, 2011: The descending stratified flow and internal hydraulic jump in the lee of the Sierras. J. Appl. Meteor. Climatol., 50, 1995-2011, doi:10.1175/JAMC-D-10-05005.1.

Baines, P. G., 1998: Topographic Effects in Stratified Flows. Cambridge University Press, $500 \mathrm{pp}$.

_ 2016: Internal hydraulic jumps in two-layer systems. J. Fluid Mech., 787, 1-15, doi:10.1017/jfm.2015.662.

Chang, M.-H., R.-C. Lien, Y. J. Yang, T. Y. Tang, and J. Wang, 2008: A composite view of surface signatures and interior properties of nonlinear internal waves: Observations and applications. J. Atmos. Oceanic Technol., 25, 1218-1227, doi:10.1175/2007JTECHO574.1.

Chaudhry, M. H., 2007: Open-Channel Flow. Springer, 523 pp.

Chow, V. T., 1959: Open-Channel Hydraulics. McGraw-Hill, 680 pp.

Cudaback, C. N., and D. A. Jay, 1996: Formation of the Columbia River plume - Hydraulic control in action? Buoyancy Effects on Coastal and Estuarine Dynamics, D. G. Aubrey and C. T. Friedrichs, Eds., Coastal Estuarine Studies Series, Vol. 53, 139-154, doi:10.1029/CE053p0139.

Cummins, P. F., and L. Armi, 2010: Upstream internal jumps in stratified sill flow: Observations of formation, evolution, and release. J. Phys. Oceanogr., 40, 1419-1426, doi:10.1175/ 2010JPO4435.1.

,$- \ldots$, and S. Vagle, 2006: Upstream internal hydraulic jumps. J. Phys. Oceanogr., 36, 753-769, doi:10.1175/JPO2894.1.

Defina, A., and D. P. Viero, 2010: Open channel flow through a linear contraction. Phys. Fluids, 22, 036602, doi:10.1063/ 1.3370334.

Drobinski, P., C. Flamant, J. Dusek, P. H. Flamant, and J. Pelon, 2001: Observational evidence and modelling of an internal hydraulic jump at the atmospheric boundary-layer top during a tramontane event. Bound.-Layer Meteor., 98, 497515, doi:10.1023/A:1018751311924.

Farmer, D. M., and J. D. Smith, 1980: Tidal interaction of stratified flow with a sill in Knight Inlet. Deep-Sea Res., 27A, 239-254, doi:10.1016/0198-0149(80)90015-1.

Farquharson, G., H. Deng, Y. Goncharenko, and J. Mower, 2014: Measurements of the nearshore ocean with FMCW ATI SAR. Proc. EUSAR 2014; 10th European Conf. on Synthetic Aperture Radar, Berlin, Germany, IEEE, 1-4.

Garvine, R. W., 1981: Frontal jump conditions for models of shallow, buoyant surface layer hydrodynamics. Tellus, 33, 301312, doi:10.1111/j.2153-3490.1981.tb01753.x.

_ _ 1982: A steady state model for buoyant surface plume hydrodynamics in coastal waters. Tellus, 34A, 293-306, doi:10.1111/j.2153-3490.1982.tb01818.x.

Gelfenbaum, G., D. Finlayson, P. Dartnell, E. Carlson, and A. Stevens, 2015: Bathymetry and backscatter from 2013 interferometric swath bathymetry systems survey of Columbia River mouth, Oregon and Washington. U.S. Geological Survey data set, accessed 5 July 2015, doi:10.5066/F7T72FHB.
Geyer, W. R., R. P. Signell, and G. C. Kineke, 1997: Lateral trapping of sediment in partially mixed estuary. Proc. Eighth Int. Biennial Conf. on Physics of Estuaries and Coastal Seas, The Hague, Netherlands, USGS, 115-124.

Hofmeister, R., H. Burchard, and J.-M. Beckers, 2010: Non-uniform adaptive vertical grids for 3D numerical ocean models. Ocean Modell., 33, 70-86, doi:10.1016/j.ocemod.2009.12.003.

IOC, SCOR, and IAPSO, 2010: The International Thermodynamic Equation of Seawater-2010: Calculation and use of thermodynamic properties. Intergovernmental Oceanographic Commission, Manuals and Guides 56, 220 pp. [Available online at http://www.teos-10.org/pubs/TEOS-10_Manual.pdf.]

Ippen, A. T., and D. R. Harleman, 1956: Verification of theory for oblique standing waves. Trans. Amer. Soc. Civ. Eng., 121, 678-694.

Jessup, A., and Coauthors, 2012: DARLA: Data Assimilation and Remote Sensing for Littoral Applications. 2012 Fall Meeting, San Francisco, CA, Amer. Geophys. Union, Abstract OS14A-01.

Kärnä, T., A. M. Baptista, J. E. Lopez, P. J. Turner, C. McNeil, and T. B. Sanford, 2015: Numerical modeling of circulation in high-energy estuaries: A Columbia River estuary benchmark. Ocean Modell., 88, 54-71, doi:10.1016/j.ocemod.2015.01.001.

Klemp, J. B., R. Rotunno, and W. C. Skamarock, 1997: On the propagation of internal bores. J. Fluid Mech., 331, 81-106, doi:10.1017/S0022112096003710.

Klymak, J. M., and M. C. Gregg, 2001: Three-dimensional nature of flow near a sill. J. Geophys. Res. Oceans, 106, 22 295-22 311, doi:10.1029/2001JC000933.

Kundu, P. K., and I. M. Cohen, 2004: Fluid Mechanics. 3rd ed. Elsevier Academic Press, 759 pp.

Lamb, K. G., 2000: Conjugate flows for a three-layer fluid. Phys. Fluids, 12, 2169-2185, doi:10.1063/1.1287652.

Lyzenga, D. R., 1998: Effects of intermediate-scale waves on radar signatures of ocean fronts and internal waves. J. Geophys. Res. Oceans, 103, 18 759-18 768, doi:10.1029/98JC01189.

MacDonald, D. G., and W. R. Geyer, 2005: Hydraulic control of a highly stratified estuarine front. J. Phys. Oceanogr., 35, 374387, doi:10.1175/JPO-2692.1.

Marmorino, G., C. Shen, N. Allan, F. Askari, D. Trizna, C. Trump, and L. Shay, 1998: An occluded coastal oceanic front. J. Geophys. Res. Oceans, 103, 21 587-21600, doi:10.1029/ 98JC02099.

, C. Trump, and D. Trizna, 1999: Preliminary observation of a tidal intrusion front inside the mouth of the Chesapeake Bay. Estuaries, 22, 105-112, doi:10.2307/1352931.

Miles, J. W., 1961: On the stability of heterogeneous shear flows. J. Fluid Mech., 10, 496-508, doi:10.1017/S0022112061000305.

Nash, J. D., and J. N. Moum, 2001: Internal hydraulic flows on the continental shelf: High drag states over a small bank. J. Geophys. Res., 106, 4593-4611, doi:10.1029/1999JC000183.

Nelson, B. G., 2009: Observations on the evolution of shoaling nonlinear internal waves in Massachusetts Bay using shipboard X-band radar. M.S. thesis, College of Earth, Ocean and Atmospheric Sciences, Oregon State University, 49 pp. [Available online at http://hdl.handle.net/1957/13731.]

Nicolau del Roure, F., S. A. Socolofsky, and K.-A. Chang, 2009: Structure and evolution of tidal starting jet vortices at idealized barotropic inlets. J. Geophys. Res., 114, C05024, doi:10.1029/2008JC004997.

Ogden, K. A., and K. R. Helfrich, 2016: Internal hydraulic jumps in two-layer flows with upstream shear. J. Fluid Mech., 789, 6492, doi:10.1017/jfm.2015.727.

Pan, J., and D. A. Jay, 2009: Dynamic characteristics and horizontal transports of internal solitons generated at the Columbia 
River plume front. Cont. Shelf Res., 29, 252-262, doi:10.1016/ j.csr.2008.01.002.

Partch, E. N., and J. D. Smith, 1978: Time dependent mixing in a salt wedge estuary. Estuarine Coastal Mar. Sci., 6, 3-19, doi:10.1016/0302-3524(78)90038-5.

Ramos, R. J., B. Lund, and H. C. Graber, 2009: Determination of internal wave properties from X-band radar observations. Ocean Eng., 36, 1039-1047, doi:10.1016/j.oceaneng.2009.07.004.

Sánchez-Garrido, J. C., G. Sannino, L. Liberti, J. García Lafuente, and L. Pratt, 2011: Numerical modeling of three-dimensional stratified tidal flow over Camarinal Sill, Strait of Gibraltar. J. Geophys. Res., 116, C12026, doi:10.1029/2011JC007093.

Smyth, W., J. Moum, and J. Nash, 2011: Narrowband oscillations in the upper equatorial ocean. Part II: Properties of shear instabilities. J. Phys. Oceanogr., 41, 412-428, doi:10.1175/ 2010JPO4451.1.

Sumner, E., and Coauthors, 2013: First direct measurements of hydraulic jumps in an active submarine density current. Geophys. Res. Lett., 40, 5904-5908, doi:10.1002/2013GL057862.

Watson, G., and I. Robinson, 1990: A study of internal wave propagation in the Strait of Gibraltar using shore-based marine radar images. J. Phys. Oceanogr., 20, 374-395, doi:10.1175/1520-0485(1990)020<0374:ASOIWP>2.0.CO;2.

White, B. L., and K. R. Helfrich, 2014: A model for internal bores in continuous stratification. J. Fluid Mech., 761, 282-304, doi:10.1017/jfm.2014.599.

Yih, C.-S., and C. Guha, 1955: Hydraulic jump in a fluid system of two layers. Tellus, 7A, 358-366, doi:10.1111/j.2153-3490.1955.tb01172.x. 